\title{
Diagnóstico do sistema de macrodrenagem do ribeirão São João em Porto Nacional/TO: um estudo de caracterização e do seu estado de conservação
}

As cidades devem possuir sistemas de escoamento das águas pluviais eficientes e sustentáveis, capazes de se adaptarem com a evolução da cidade, para suprir as necessidades da população no decorrer do tempo e garantir uma qualidade de vida adequada. O objetivo desse trabalho é caracterizar e realizar o estudo da bacia urbana de drenagem do ribeirão São João em Porto Nacional/TO, e avaliar o seu estado de conservação. A determinação da área da bacia se deu por meio da análise do Modelo Digital de Terreno (MDT) do município, gerado a partir das curvas de nível urbanas, de 1 em 1 metro, fornecidas pelo Geomais ${ }^{\circledR}$ de Porto Nacional/TO. Os processamentos espaciais das informações foram desenvolvidos pelo programa QGIS ${ }^{\oplus}$, um programa de Sistema de Informação Geográfica (SIG) Os parâmetros morfométricos calculados, apontam que a bacia do Ribeirão São João em Porto Nacional/TO possui baixa tendência de ocorrerem enchentes ou inundações.

Palavras-chave: Macrodrenagem; Geoprocessamento; Morfometria.

\section{Diagnosis of the macro-drainage system of the São João stream in Porto Nacional/TO: a characterization study and its conservation status}

Cities must have efficient and sustainable rainwater drainage systems, capable of adapting to the city's evolution, to meet the needs of the population over time and guarantee an adequate quality of life. The objective of this work is to characterize and carry out the study of the urban drainage basin of the São João stream in Porto Nacional/TO, and to evaluate its conservation status. The determination of the basin area was made through the analysis of the Digital Land Model of the municipality, generated from the urban level curves, of 1 in 1 meter, provided by Geomais ${ }^{\circledR}$ of Porto Nacional/TO. The spatial processing of information was developed by the QGIS ${ }^{\circledR}$ program, a Geographic Information System (GIS) program. The calculated morphometric parameters show that the Ribeirão São João basin in Porto Nacional/TO has a low tendency to occur floods or floods.

Keywords: Macrodrainage; Geoprocessing; Morphometry.

Topic: Desenvolvimento, Sustentabilidade e Meio Ambiente

Reviewed anonymously in the process of blind peer
Received: $\mathbf{1 1 / 1 1 / 2 0 2 0}$

Approved: 09/02/2021

Gabriel Lopes Coelho Viana

ITPAC Porto Nacional, Brasil

http://lattes.cnpq.br/5171199867586528

0007274@acad.itpacporto.com.br

Alesi Teixeira Mendes

ITPAC Porto Nacional, Brasil

http://lattes.cnpq.br/2473113080999082

http://orcid.org/0000-0002-5632-7235

alesi.mendes@itpacporto.edu.br

d

DOI: 10.6008/CBPC2237-9290.2021.001.0011
Referencing this:

VIANA, G. L. C.; MENDES, A. T.. Diagnóstico do sistema de macrodrenagem do ribeirão São João em Porto Nacional/TO: um estudo de caracterização e do seu estado de conservação. Natural Resources, v.11, n.1, p.82-91, 2021. DOI:

http://doi.org/10.6008/CBPC2237-9290.2021.001.0011 
Diagnóstico do sistema de macrodrenagem do ribeirão São João em Porto Nacional/TO: um estudo de caracterização e do seu estado de

\section{INTRODUÇÃO}

A urbanização, fenômeno que tem ocorrido de forma acelerada e desordenada em diversas cidades brasileiras impacta direta e abruptamente o comportamento do ciclo hidrológico nas bacias hidrográficas. As implicações das interferências antrópicas nas bacias são geralmente indesejadas dentro do cotidiano das cidades como, por exemplo, o escoamento superficial acentuado, pontos de alagamento e inundações, e arraste de sedimento para vias de circulação de veículos.

O sistema de drenagem de uma cidade é um parâmetro de destaque para aferir os problemas oriundos da expansão urbana desordenada. A ineficiência desse sistema se manifesta imediatamente após o início de chuvas significativas e os transtornos são logo percebidos pela população.

Por muitos anos, em vários países, inclusive no Brasil, a drenagem urbana das cidades foi tratada de maneira secundária, no âmbito de divisão do solo para o uso urbano. $\mathrm{O}$ crescimento desordenado de municípios associado à acelerada expansão das áreas urbanizadas resultou em uma falta de planejamento no setor de drenagem urbana, deixando-a para segundo plano (CANHOLI, 2015).

Para Canholi (2015), o bom funcionamento do sistema de micro e macrodrenagem de uma zona urbana, é indispensável o planejamento integrado e abrangente. Contudo, a falta deste planejamento tem ocasionado o estado preocupante das áreas urbanas brasileiras, com a ocorrência de enchentes frequentes.

A gestão das águas pluviais na conjuntura atual se configura como uma indispensável ferramenta estruturante para a saúde pública. Além disso, a Lei do Saneamento Básico também estabeleceu os municípios como os titulares dos serviços públicos de saneamento básico e, portanto, responsáveis por desenvolver as diretrizes, programas e projetos para a melhoria da salubridade ambiental do município.

Conforme destaca Mendes (2019), o estudo de medidas com baixo impacto para o manejo de águas pluviais é uma solução para as problemáticas vistas nas cidades. De fato, é essencial que as águas das chuvas nas áreas urbanas sejam devidamente drenadas, entretanto é preciso que os sistemas de drenagem sejam pensados de outra forma para obter resultados diferentes e melhores.

As cidades devem possuir sistemas de escoamento das águas pluviais eficientes e sustentáveis, capazes de se adaptarem com a evolução da cidade, para suprir as necessidades da população no decorrer do tempo e garantir uma qualidade de vida adequada.

Dessa maneira, o objetivo desse trabalho é caracterizar e realizar o estudo da bacia urbana de drenagem do ribeirão São João em Porto Nacional - TO, e avaliar o seu estado de conservação.

\section{METODOLOGIA}

\section{Caracterização do município em estudo}

O município de Porto Nacional tem uma área de $4.442,62 \mathrm{~km}^{2}$, com população estimada de 53.316 habitantes, sendo considerada a quarta maior cidade em aspectos populacionais do Tocantins (IBGE, 2020). O clima tem o clima C2WA'a", segundo o Método de Thornthwaite, com o clima úmido com poucas chuvas no inverno, tem evapotranspiração potencial média anual na faixa de $1.500 \mathrm{~mm}$, se dividindo no verão em 
Diagnóstico do sistema de macrodrenagem do ribeirão São João em Porto Nacional/TO: um estudo de caracterização e do seu estado de

$420 \mathrm{~mm}$ durante três meses consecutivos de temperaturas superiores (TOCANTINS, 2008).

A precipitação pluviométrica anual na cidade varia em torno de $1500 \mathrm{~mm}$, em seu centro e sudeste, e $1800 \mathrm{~mm}$ em seu Norte, com incidência de mais de 80 \% entre o período chuvoso de outubro a abril, onde podem ou ocorrem fortes chuvas com relativa capacidade erosiva. A predominância da vegetação na cidade é a do Cerrado (SEPLAN, 2012).

O Ribeirão São João, que percorre o município, se configura a única fonte de abastecimento da cidade por meio de captação superficial. Com o acelerado crescimento populacional e o aumento do cultivo da soja e milho principalmente, aparece uma dúvida sobre o tratamento de suas águas para captação, abastecimento e como está o estado de sua fauna e flora (BALDUíNO et al., 2019).

\section{Caracterização da bacia de estudo}

A área de estudo escolhida nessa pesquisa é a bacia de drenagem do Ribeirão São João situada a sudeste do município de Porto Nacional. Esta bacia localiza-se no limite direito do reservatório da Usina de Luís Eduardo Magalhães, tendo sua foz incorporada à área urbana da cidade, contribuindo diretamente no trecho do Rio Tocantins.

Possui sua nascente em zona rural, na fazenda Pilão, em uma elevação de aproximadamente 601 m, em seu decorrer no sentido Leste-Oeste atravessa outras propiedades rurais e bairros bem conhecidos na cidade como Jardim Querido, Jardim Umuarama, Santa Helena e Vila Nova desaguando no reservatório UHE - Luís Eduardo Magalhães em uma elevação de 212 m acima do nível do mar (SILVA, 2015; CARVALHO et al., 2016).

Possui um corpo hídrico bastante rico, sendo constituído por vários cursos d'água que compõe seu sistema drenagem. Dentre eles cabe citar os rios principais: o Tocantins, Matança e Água Suja; e também sete Ribeirões: o do Carmo, Santa Luzia, dos Mangues, Manguinho, Conceição, Chupé e São João (SEPLAN, 2012).

A infraestrutura da drenagem pluvial da região estudada é composta basicamente pelas vias públicas pavimentas e com meio-fio e sarjeta, não contando com redes subterrâneas de drenagem. Logo, o escoamento se dá majoritariamente pela superfície até o Ribeirão São João que recebe o escoamento superficial da bacia de drenagem.

A determinação da área da bacia se deu por meio da análise do Modelo Digital de Terreno (MDT) do município, gerado a partir das curvas de nível urbanas, de 1 em 1 metro, fornecidas pelo Geomais ${ }^{\circledR}$ de Porto Nacional- TO. Os processamentos espaciais das informações foram desenvolvidas pelo programa QGIS ${ }^{\circledR}$, um programa de Sistema de Informação Geográfica (SIG).

O perfil hidrográfico da bacia foi baseado em informações secundárias extraídas da pesquisa desenvolvida por Balduíno (2019), em que foi feito o levantamento barimétrico do Ribeirão São João por meio do conhecido método acústico empregando o Perfilador Acústico Doppler. Juntamente com o software do aparelho, denominado RiverSurveyorLive, gerando as planilhas com os resultados obtidos em campo em 
dezembro de 2017.

Detalhes importantes basearam o desenvolvimento da análise morfométrica da bacia, começando com a caracterização geométrica que determinou o perímetro, a área, extensão da talvenge principal e da bacia, assim como seu Kf (fator de forma), seu Kc (coeficiente de compacidade), a Dh (densidade hidrográfica) e o Ic (Índice de Circularidade). Na caracterização do relevo foram observados parâmetros de declividade e hipsometria.

O fator de forma (Kf) estabelece uma relação entre o formato da bacia com a de uma circunferência, sendo encontrado através da divisão da área de drenagem por um valor adquirido entre o comprimento do delta ao ponto longínquo ao longo do perímetro da bacia (TONELLO et al., 2006).

Para carcular o fator de forma (Kf) são dispostas duas fórmulas demonstradas abaixo:

$$
K f=\frac{\bar{L}}{L} \text { ou } K f=\frac{A}{L^{2}}
$$

Onde:

$\mathrm{Kf}=$ Fator de forma; $\bar{L}=$ Largura Média da Bacia; $L=$ Comprimento do eixo da Bacia; $A=$ Área de drenagem $\left(\mathrm{Km}^{2}\right)$; $\mathrm{L}=$ Comprimento do axial da bacia $(\mathrm{Km})$.

Segundo Tonello et al. (2006), o coeficiente de compacidade (Kc) associa a forma da bacia estudada ao modelo circular ou alongado. Quando em uma análise o valor de Kc resultar em valores aproximados a 1,0, já é compreendido que sua forma tende a ser circular, assim tendo maiores riscos de enchente, quando apresentar valores maiores que 1,0, está bacia manifesta formato irregular e alongado.

Já para obter-se o coeficiente de compacidade (Kc), é utilizada a fórmula abaixo:

$$
K c=0,28 \frac{P}{\sqrt{A}}
$$

Onde: Kc = Coeficiente de compacidade; $\mathrm{P}=$ Perímetro $(\mathrm{Km})$; $\mathrm{A}=$ Área de drenagem $\left(\mathrm{Km}^{2}\right)$.

Outra característica importante é a densidade hidrográfica (Dd) que é calculada pela seguinte forma:

$$
D h=\frac{N}{A} \quad(E q .3)
$$

Onde:

Dh = Densidade hidrográfica; $\mathrm{N}=$ Número total de rios; A = Área da bacia.

A densidade hidrográfica é a combinação expressada entre a área da bacia delimitada e o número de rios. Ela se mostra importante em demonstrar a capacidade da bacia hidrográfica de gerar novos cursos de água em função de suas características climáticas, geológicas e do solo (CASTRO et al., 2009).

Por último outro fator essencial para análise é o Índice de circularidade (Ic), que tem certa semelhança com o coeficiente de compacidade, já que os valores se aproximam à 1,0 na medida que a bacia tende ao formato circular e distanciam de 1,0 na medida que a bacia se torna mais alongada (CARDOSO et 
al., 2006). Para determiná-lo foi utilizada a seguinte equação:

$$
I c=\frac{12,57 \times A}{P^{2}}
$$

Onde:

Ic = Índice de Circularidade;

$\mathrm{A}=$ Área da bacia em $\mathrm{km}^{2}$; $P=$ Perímetro da bacia em $\mathrm{km}$.

\section{Diagnóstico do estado de conservação dos corpos hídricos}

Visitas foram feitas nos cursos de água do Ribeirão São João, para realizar o diagnóstico do estado de conservação dos corpos hídricos. Com a elaboração de um relatório fotográfico feito em campo e coleta das coordenadas geográficas por meio de GPS.

As coferências in loco foram realizadas entre os meses de outubro e novembro de 2020, período do início das chuvas do estado. Este período chuvoso se estende de outubro até abril, em que há uma maior pluviosidade nos meses de Dezembro e Janeiro. O mês de outubro possui em média de precipitação $125 \mathrm{~mm}$, assim tornando-se $07^{\circ}$ mês no quesito de maiores índices pluviométricos (MARCUZZO et al., 2013).

\section{RESULTADOS E DISCUSSÃO}

A bacia de drenagem do Ribeirão São João possui área de $81,71 \mathrm{~km}^{2}$, com perímetro de $84,72 \mathrm{~km}$ e com amplitude máxima de 386 metros em seu canal principal. A porção da área urbana da cidade de Porto Nacional - TO inserida na bacia apresenta uma área de $13,68 \mathrm{~km}^{2}$, representando $15 \%$ de sua área total. 0 talvegue principal do mede cerca de Ribeirão São João $15 \mathrm{~km}$. Os valores encontrados são próximos ao apresentado por Leite et al. (2013).

A Figura 1, a seguir, apresenta o mapa da bacia delimitada a partir do MDT utilizado.

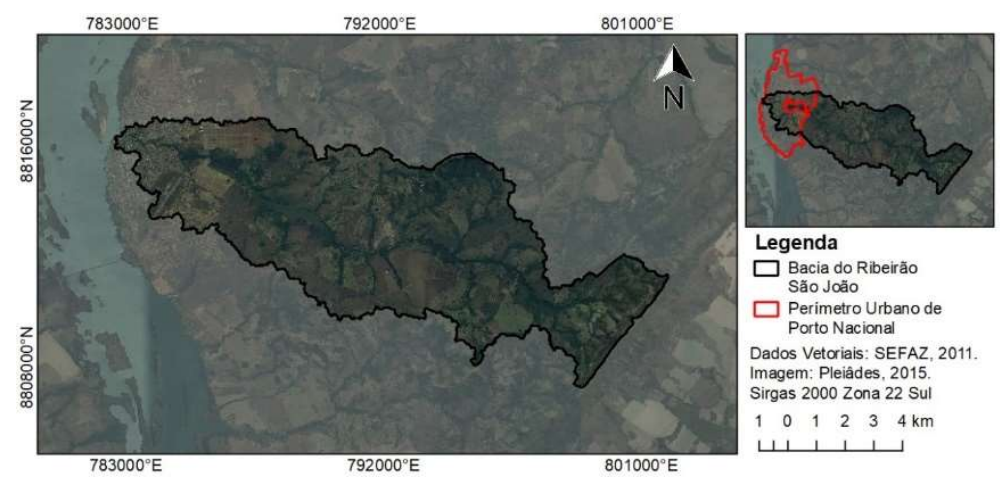

Figura 1: Mapa da bacia do Ribeirão São João.

As características morfométricas estudadas da bacia do Ribeirão São João com todos seus resultados, podem ser observados na Tabela 1.

Tabela 1: Parâmetros morfométricos da bacia.

\begin{tabular}{ll}
\hline Parâmetros & Valores \\
\hline Área Total $\left(\mathrm{km}^{2}\right)$ & 81,71 \\
Perímetro total $(\mathrm{km})$ & 84,72 \\
Talvenge principal $(\mathrm{km})$ & 15 \\
Dh $(\mathrm{km})$ & 2,78
\end{tabular}


Diagnóstico do sistema de macrodrenagem do ribeirão São João em Porto Nacional/TO: um estudo de caracterização e do seu estado de

\begin{tabular}{lr} 
Kf & 0,36 \\
Kc & 2,62 \\
Ic & 0,14 \\
\hline Dh - Densidade Hidrográfica; & \\
Kf - Fator de Forma; Kc- Coeficiente de Compacidade; & \\
Ic - Índice de Circularidade. & \\
\hline
\end{tabular}

Além disso, a vazão média encontrada para a seção estudada do Ribeirão São João foi de $1,55 \mathrm{~m}^{3} / \mathrm{s}$, segundo dados de Balduíno (2019). Os demais dados encontrados estão na Tabela 2, com o resumo de cada passagem.

Tabela 2: Valores de vazão em diferentes travessias do Ribeirão São João.

\begin{tabular}{l|l|l|l|l|l|l}
\hline Travessia & Margem de início & Vazão Superficial & Vazão Meio & Vazão Fundo & Vazão Total & Área $\left(\mathbf{m}^{\mathbf{2}}\right)$ \\
\hline 1 & Esquerda & 0,031 & 1,112 & 0,418 & 1,561 & 491,634 \\
\hline 2 & Direita & 0,029 & 1,094 & 0,420 & 1,543 & 487,173 \\
\hline 3 & Esquerda & 0,032 & 1,107 & 0,441 & 1,560 & 490,679 \\
\hline 4 & Direita & 0,033 & 1,119 & 0,410 & 1,562 & 489,460 \\
\hline 5 & Esquerda & 0,033 & 1,087 & 0,424 & 1,544 & 489,975 \\
\hline 6 & Direita & 0,032 & 1,098 & 0,410 & 1,540 & 483,932 \\
\hline 7 & Esquerda & 0,031 & 1,099 & 0,410 & 1,540 & 487,134 \\
\hline 8 & Direita & 0,030 & 1,089 & 0,430 & 1,549 & 486,438 \\
\hline 9 & Esquerda & 0,031 & 1,107 & 0,390 & 1,528 & 485,810 \\
\hline 10 & Direita & 0,034 & 1,103 & 0,440 & 1,577 & 488,167 \\
\hline Média & 0,032 & 1,102 & 0,4193 & $\mathbf{1 , 5 5 2}$ & 488,040 \\
\hline Desvio Padrão & 0,014 & 0,009 & 0,0146 & 0,016 & 2,272 \\
\hline \multicolumn{2}{l}{ Coeficiente de Variação (\%) } & 4,52 & 0,871 & 3,501 & $\mathbf{1 , 0 3 9}$ & 0,465 \\
\hline
\end{tabular}

Fonte: Balduíno (2019).

A bacia possui coeficiente de capacidade $(\mathrm{Kc})$ superior a 1,0, indicando que está apresenta um formato irregular e alongado, aumentando a segurança de suas margens, já que demonstra um baixo potencial de ocorrerem inundações ou enchentes e não há significativa afluência de deflúvio.

Com seu valor de Fator de Forma (Kf) igual a $(0,36)$, bem afastado da unidade, pode-se considerar que nesta bacia há raras chances de ocorrerem inundações em eventos de picos de cheia e também reforça seu formato não circular.

O índice de Circularidade (Ic) da bacia apresenta valor de 0,14, bem abaixo da média de 0,51 que define o ponto em que quanto maior o decrécimo do valor, mais há a tendência de as bacias serem alongadas. Como este é o nosso caso, estes aspectos favorecem o processo de escoamento da água pelo Ribeirão.

A análise da hipsometria da bacia permite atestar que a fisionomia do relevo é preponderantemente plano com a paisagem pouco acidentada, já que a maioria da sua bacia apresenta altitudes baixas, não ultrapassando a faixa de 100 a 200 m no terreno urbano. Refletindo assim nas elevações do relevo, que através do escoamento principal é o responsável pelo desnível da nascente (montante) em relação com a foz (jusante). A Figura 2 apresenta o Mapa de Hipsometria.

Na observação deste mapa, podemos identificar que próximo ao exutório são encontras em variância duas faixas de elevação do terreno ( 1 até $100 \mathrm{~m}$ e 100 até $200 \mathrm{~m}$ ) compreendendo a maior parte da bacia. Em comparação com as outras amplitudes altimétricas não é encontrada significativa diferenciação, somente elevando seu relevo fora da zona urbana. 


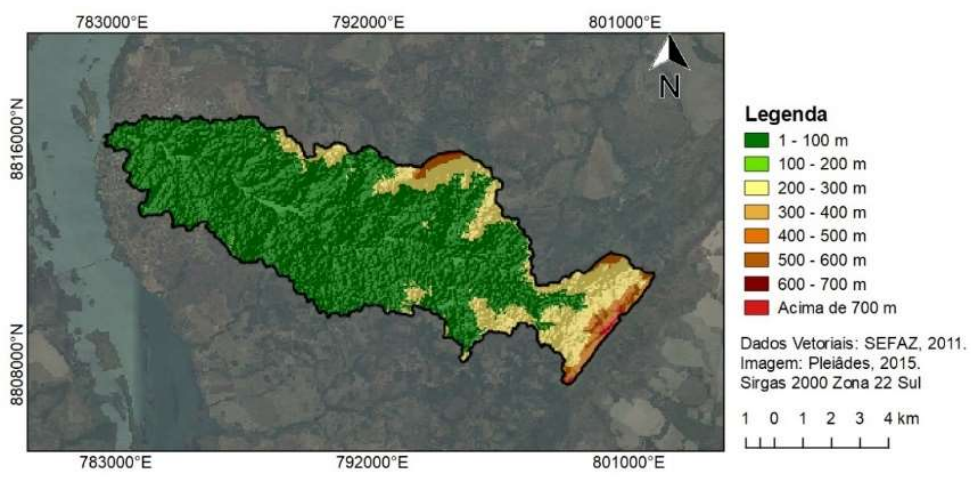

Figura 2: Mapa de Hipsometria.

Com relação a declividade da bacia, a representação gráfica foi gerada em graus decimais e dividida em 6 classes de acordo com o sistema brasileiro de classificação de solos da Embrapa (2018), como pode ser visualizado no mapa abaixo (Figura 3).

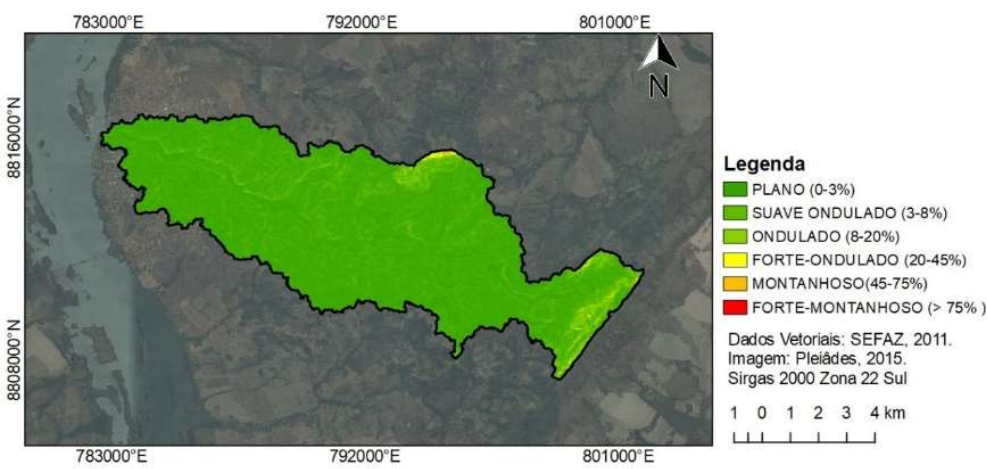

Figura 3: Mapa de Declividade.

A bacia hidrográfica possui a maior parte de sua área com declividade plana (0-3\%) ou suavemente ondulada (3-8\%). Evidenciando o resultado de diversas ações erosivas que desgastaram o relevo até resultar em declividades baixas. Uma das causas da baixa amplitude de declividade também está ligada a localização territorial da bacia à margem do Rio Tocantins, situada em uma área conhecida geologicamente como unidade de Depressão do Tocantins (BRASIL, 1981).

Pode-se notar que as maiores taxas de declividade estão localizadas em áreas que concentram maior elevação altimétrica, sendo o caso retratado referente à face norte da bacia do Morro São João, e a leste, cobrindo sua nuance ocidental da Serra de Monte do Carmo (SILVA, 2010).

A correlação entre os dois mapas evidência um terreno majoritariamente plano com uma declividade de plana para suavemente ondulada em direção ao exutório principal (UHE Lajeado, Rio Tocantins), onde todo o escoamento é levado por ação da gravidade, já que não é constado nenhum dispositivo de drenagem convencional ou sustentável.

A bacia hidrográfica do Ribeirão São João corta a região central do município, e os impactos da presença do homem pode ser facilmente identificada, por exemplo no trecho apresentado a seguir evidenciando a presença de lixo disposto em seu canal, dificultando o escoamento superficial, localizado na TO - $255\left(10^{\circ} 42^{\prime} 07.8^{\prime \prime S} 48^{\circ} 23^{\prime} 49.2^{\prime \prime} \mathrm{W}\right)$ na parte inferior da ponte do anel viário, conforme registrado na Figura 4. 
Diagnóstico do sistema de macrodrenagem do ribeirão São João em Porto Nacional/TO: um estudo de caracterização e do seu estado de conservação

VIANA, G. L. C.; MENDES, A. T.

Em outro trecho é possível observar o crescimento de vegetação no leito do Ribeirão, devido à falta de manutenção periódica do trecho (Figura 5). Essa flora atrapalha e impede na velocidade do escoamento do deflúvio, aumentando assim a área molhada e tornando este local passível há possíveis transbordamentos futuros. A imagem é localizada na Rua Dom Alano nas coordenadas geográficas $10^{\circ} 41^{\prime} 59.3^{\prime \prime} \mathrm{S} 48^{\circ} 24^{\prime} 28.8^{\prime \prime} \mathrm{W}$.
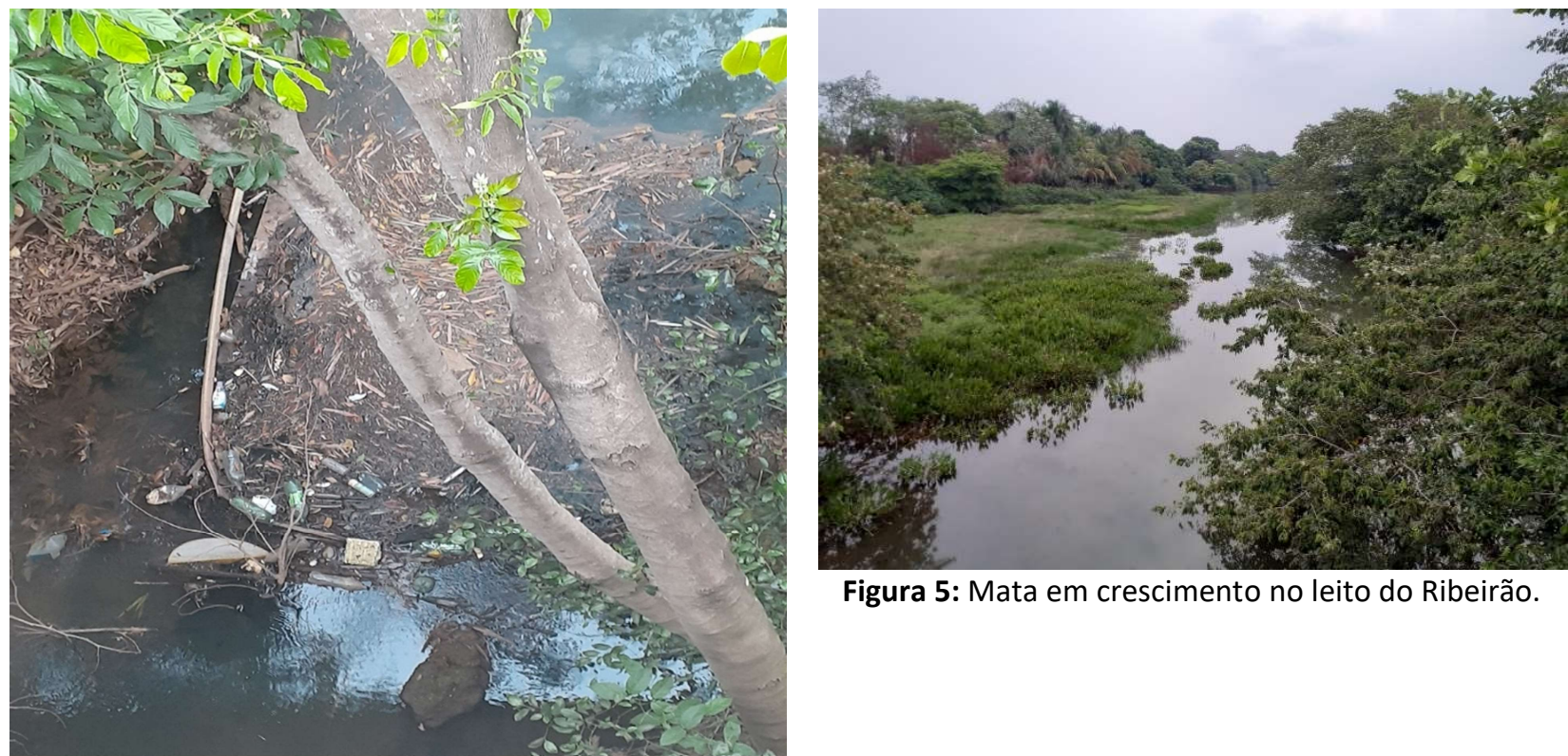

Figura 5: Mata em crescimento no leito do Ribeirão.

Figura 4: Foco de lixo no Ribeirão São João.

Ao visitar o seu trecho na parte central da cidade, que cruza a Avenida Padre Luso $\left(10^{\circ} 42^{\prime} 05.3^{\prime \prime S}\right.$ $\left.48^{\circ} 24^{\prime} 24.6^{\prime \prime} \mathrm{W}\right)$, foi possível observar uma certa supressão da mata nativa e o início de um processo erosivo (Figura 6 e 7). Com o período de chuvas se aproximando é bem provável que deslocamentos de terra possam ocorrer, transformando em uma problemática maior.

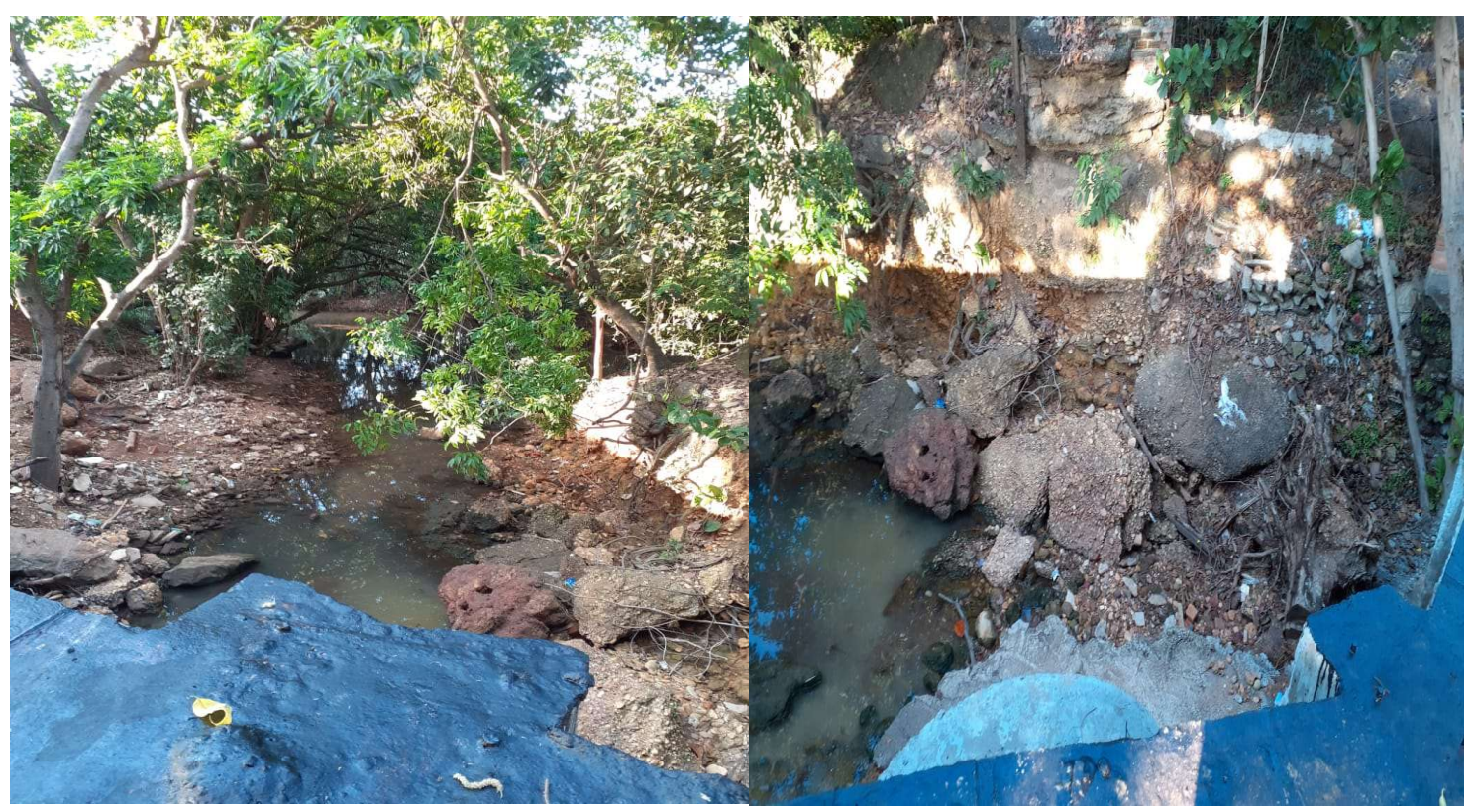

Figura 6 e 7: Pontos erosivos em trecho da bacia.

A vegetação ao redor do domínio d'agua no Ribeirão São João tem na maioria de sua extensão apresentado ótima conservação, respeitando a distância mínima para construção de edificações e 
protegendo a fauna aquática. Como podemos ver nas Figuras 7 e 8.

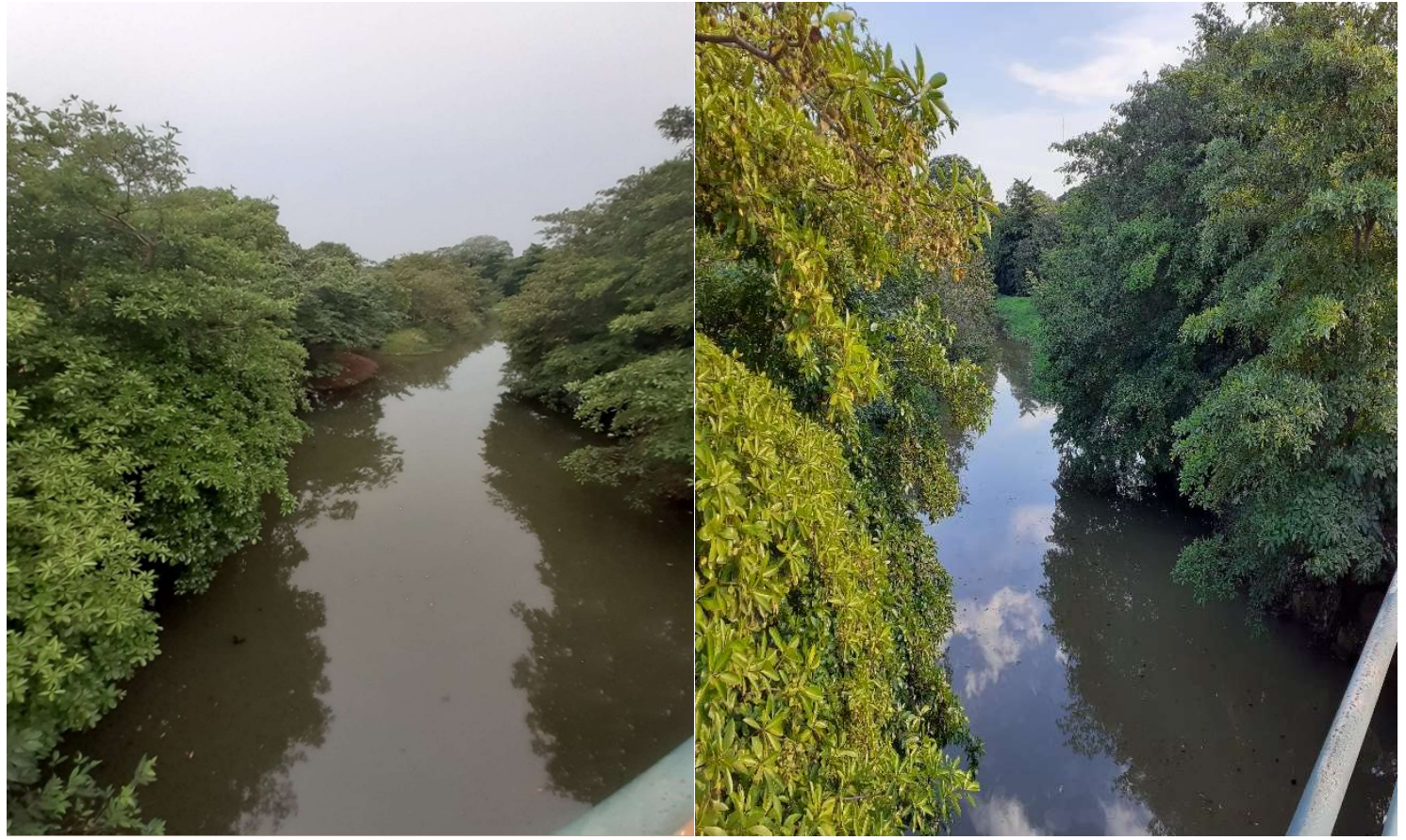

Figura 6 e 7: Vegetação conservada na bacia.

\section{CONCLUSÕES}

Os parâmetros morfométricos calculados, apontam que a bacia do Ribeirão São João em Porto Nacional- TO possui baixa tendência de ocorrerem enchentes ou inundações, até em ocasiões de pico de cheia, devido ao seu fator de forma associado ao coeficiente de compacidade, indicando seu formato alongado e irregular, o que favorece o escoamento superficial.

Com relação as características do relevo, a baixa elevação altimétrica do terreno está ligada à sua declividade suavemente ondulada em que favorece a maior velocidade de escoamento, demonstrando que a bacia é seu próprio sistema de drenagem.

É possível observar que em grande parte da extensão do Ribeirão São João é preservada sua flora natural, sendo um bom ponto bem positivo. Entretanto, em visitas ao local, foi possível identificar diversas problemáticas que prejudicam o bom escoamento das águas, como pontos de erosão, focos de lixo e o crescimento de matas em seu leito.

Em virtude da grande importância desta bacia para o município, já que é sua única fonte de abastecimento, é de fundamental importância a manutenção periódica de sua parte urbanizada, com políticas públicas de combate à poluição e conservação da sua flora que está em ótimo estado.

\section{REFERÊNCIAS}

BALDUÍNO, Â. R.; SOUZA, V. V. V. S.; CARVALHO, A. C. V.; BRITO, A. H. C.. Caracterização de Resíduos Químicos nos Sedimentos da Barragem de Abastecimento de Água no Ribeirão São João no Município de Porto Nacional, Tocantins. In: BALDUINO, Â. R.; SOUZA, M. V. V. V.; CARVALHO, A. C. V.; BRITO, A. H. C.. Engenharia no Século XXI. Belo Horizonte: Poisson, 2019. p.43-55.
BALDUINO, Â. R.. Análise dos impactos da agricultura na qualidade da água do reservatório de abastecimento de água no município de Porto Nacional - Tocantins. Tese (Doutorado em Ciência do Ambiente) - Universidade Federal do Tocantins, Palmas, 2019. 
BRASIL. Ministério das Minas e Energia. Projeto

RADAMBRASIL. Folha SC-22 - Tocantins. Rio de Janeiro:

Ministério das Minas e Energia, 1981.

CANHOLI, A.. Drenagem urbana e controle de enchentes. Oficina de textos, 2015.

CARDOSO, C. A.; DIAS, H. C. T.; SOARES, C. P. B.; MARTINS, S. V.. Caracterização morfométrica da bacia hidrográfica do rio Debossan, Nova Friburgo, RJ. Revista Árvore, v.30, n.2, p.241-248, 2006.

CARVALHO, A. P.; BALDUINO, Â. R.; MACIEL, G. F.; PICANÇO, A. P.. Avaliação da poluição em rios utilizando índices de qualidade da água: um estudo de caso no ribeirão São João em Porto Nacional-TO. Revista Geociências - Unesp, São Paulo, v.3, n.35, p.472-484, 2016.

CASTRO, S. B.; CARVALHO, T. M.. Análise morfométrica e geomorfologia da bacia hidrográfica do rio Turvo - GO, através de técnicas de sensoriamento remoto e geoprocessamento. Scientia Plena, Goiânia, v.5, n.2, p.1-7, 2009.

EMBRAPA. Sistema Brasileiro de Classificação de Solos. 5 ed. Brasília: Embrapa, 2018.

IBGE. Instituto Brasileiro de Geografia e Estatística. Cidades e Estados. Porto Nacional: IBGE, 2020.

LEITE, E. F.; CARVALHO, E. M.. Mapeamento do uso e cobertura da terra na bacia hidrográfica do Ribeirão São João, Porto Nacional, Tocantins. Revista Eletrônica do Curso de Geografia, Jataí, v.2, n.20, p.97-110, 2013.

MARCUZZO, F. F. N.; GOULARTE, E. R. P.. Caracterização do ano hidrológico e mapeamento espacial das chuvas nos períodos úmido e seco do estado do Tocantins. Revista Brasileira de Geografia Física, Palmas, v.6, n.1, p.91-99, 2013.

MENDES, A. T.. Dispositivos de drenagem urbana de baixo impacto para diminuição da vazão no sistema de microdrenagem da bacia urbana do córrego Brejo Comprido, Palmas-TO. Dissertação (Mestrado Profissional em Engenharia Ambiental) - Universidade Federal do Tocantins, Palmas, 2019.

SEPLAN. Base de Dados Geográficos do Tocantins. Palmas: SEPLAN, 2012.

SILVA, A. A. F.. Geoprocessamento aplicado a análise e mapeamento geomorfológico da bacia hidrográfica do Ribeirão São João-TO. Monografia (Especialização em Geografia) - Universidade Federal do Tocantins, Porto Nacional, 2010.

SILVA, A. A. F.. Geoprocessamento aplicado à análise e mapeamento geomorfológico da bacia hidrográfica do Ribeirão São João-TO. In: SIMPÓSIO BRASILEIRO DE GEOGRAFIA FÍSICA APLICADA, 16. Anais. Teresina: Revista Equador, 2015. p.63-70.

TOCANTINS. Secretaria do Planejamento. Superintendência de Planejamento e Gestão Central de Políticas Públicas: Diretoria Zoneamento Ecológico Econômico. Atlas do Tocantins: Subsídios ao Planejamento da Gestão Territorial. 5 ed. Palmas: SEPLAN, 2008.

TONELLO, K. C.; DIAS, H. C. T.; SOUZA, A. L.; RIBEIRO, C. A. A. S.; LEITE, F. P.. Morfometria da bacia hidrográfica da Cachoeira das Pombas, Guanhães-MG. Revista Árvore, Viçosa, v.30, n.5, 2006. DOI: https://doi.org/10.1590/S0100$\underline{67622006000500019}$

A CBPC - Companhia Brasileira de Produção Científica (CNPJ: 11.221.422/0001-03) detém os direitos materiais desta publicação. Os direitos referem-se à publicação do trabalho em qualquer parte do mundo, incluindo os direitos às renovações, expansões e disseminações da contribuição, bem como outros direitos subsidiários. Todos os trabalhos publicados eletronicamente poderão posteriormente ser publicados em coletâneas impressas sob coordenação da Sustenere Publishing, da Companhia Brasileira de Produção Científica e seus parceiros autorizados. Os (as) autores (as) preservam os direitos autorais, mas não têm permissão para a publicação da contribuição em outro meio, impresso ou digital, em português ou em tradução. 